\title{
Een gemankeerde wereld
}

\section{Theorieën over (on)toegankelijkheid}

\author{
Erwin Dijkstra
}

Of een samenleving toegankelijk is voor mensen met een lichamelijke of mentale functiebeperking hangt tegenwoordig nog vooral af van de prevalente maatschappelijke opvattingen over de mate waarin men deze groep dient te faciliteren. ${ }^{1} \mathrm{Als}$ de openbare ruimte (deels) ontoegankelijk is voor mensen met een functiebeperking of als maatschappelijke instituties hun behoeften en zorgen niet meenemen op gelijke voet met die van relatief gezonde mensen, kan men dit dus ten minste gedeeltelijk op het conto van het huidige denkkader schrijven. De opvattingen over de gewenste maatschappelijke positie van mensen met een functiebeperking zijn echter altijd in beweging. Dergelijke bewegingen hebben invloed op en worden weerspiegeld in wet- en regelgeving, internationale verdragen en - op termijn - de openbare ruimte en de handelswijze van instituties. ${ }^{2}$ Zulke veranderende maatschappelijke opvattingen en hun politieke invloed bestaan niet in een vacuüm, zij worden mede gevormd door theoretische ideeën en de popularisering daarvan, bijvoorbeeld door activisten. ${ }^{3}$ Eenvoudig gesteld vinden de momenteel meest invloedrijke theorieën over (on)toegankelijkheid wereldwijd hun oorsprong in het samenspel van grofweg twee bronnen: het conceptuele werk van onderzoekers binnen gehandicaptenstudies (disability studies) en de verdere uitwerking hiervan binnen het zich immer ontwikkelende programma van de gehandicaptenrechtenbeweging (disability rights movement). ${ }^{4}$ Aan de hand van deze theorieën is beschreven hoe de maatschappij de laatste jaren toegankelijker is geworden voor mensen met een functiebeperking. Daarnaast verklaren zulke theorieën waar en waarom het nog aan toegankelijkheid schort. Ook komen uit dergelijke theorieën regelmatig alternatieven voort om de wereld voor mensen met een functiebeperking toegankelijker te maken.

In deze bijdrage plaats ik de ervaringen en observaties van (on)toegankelijkheid uit de Forum-bijdrage hiernaast in deze theoretische context. Hiertoe zal ik eerst kort de ontwikkeling van de invloedrijkste theorieën over (on)toegankelijkheid schetsen en laten zien hoe deze naast de bekendere fysieke obstakels ook instituties en procedures betreffen. Vervolgens zal ik de hiernaast beschreven vorderingen en tekortkomingen in toegankelijkheid theoretisch duiden. Tot slot beschrijf ik enkele van de richtingen die in de besproken theorieën worden aangereikt om deze tekortkomingen op te lossen. Deze oplossingen komen met hun eigen haken en 
ogen, maar bieden op termijn uitzicht op een toegankelijkere maatschappij voor iedereen. ${ }^{5}$

\section{Stuivertje wisselen met modellen}

Binnen theorieën over (on)toegankelijkheid is de verschuiving van het medische naar het sociale model erg belangrijk geweest. ${ }^{6}$ Vanuit het medische model werden mensen met een lichamelijke of mentale functiebeperking vanouds als defectief gezien en moesten deze personen worden gerehabiliteerd zodat zij zo veel mogelijk 'normaal' konden functioneren. ${ }^{7}$ Deze aanpak isoleerde mensen met een functiebeperking veelal van de rest van de samenleving. ${ }^{8}$ Vanaf de jaren zestig van de vorige eeuw werd het medische model daarom aangevuld door het zogenoemde normaliseringsmodel. Dit model had als uitgangspunt dat mensen met een functiebeperking hetzelfde leven zouden moeten kunnen leiden als mensen zonder functiebeperking, los van hun medische rehabilitatie. ${ }^{9}$ Desalniettemin deelden beide modellen de nadruk op een functiebeperking als persoonlijke eigenschap. ${ }^{10} \mathrm{Men}$ sen met een functiebeperking moesten vooral aangepast worden, of geholpen worden om zich aan te passen aan de maatschappij zoals deze reeds bestond met al haar obstakels. Deze focus werd langzaamaan verdrongen - in de theorievorming althans - door het sociale model, waarbij de pendule juist de andere kant op zwaaide.

Het sociale model gaat ervan uit dat de aannames en het handelen van maatschappelijke instituties mensen, wier lichamelijke of mentale gesteldheid afwijkt van de veronderstelde norm, op achterstand zet en daarmee 'gehandicapt' maakt. ${ }^{11}$ De wereld is dus gemankeerd, niet de persoon met een functiebeperking. Met deze vaststelling wordt binnen het sociale model ook de ontoegankelijkheid van de fysieke wereld verklaard, aangezien de inrichting daarvan ontspruit aan de besluitvorming van diezelfde instituties en evenzeer geënt is op veronderstelde normen. ${ }^{12}$ Mensen met een functiebeperking zijn daarmee op zijn best bijzaak bij het ontwerpen van, bijvoorbeeld, de openbare ruimte. Een bijzaak waarvoor, bij wijze van uitzondering, eventueel aanpassingen kunnen worden gedaan. ${ }^{13}$ Dergelijke uitzonderingen hebben daarmee eerder het karakter van een gunst of liefdadigheid dan van een recht. ${ }^{14} \mathrm{Als}$ remedie hamert het sociale model op gelijke rechten voor mensen met een functiebeperking. ${ }^{15}$ Een toegankelijke fysieke wereld en instituties die de

$5 \quad$ Emens 2015, p. 69.

6 Jansen 2020, p. 36-37.

7 Silvers 1998, p. 99; Jansen 2020, p. 36.

8 Cogdell 2015, p. 176.

9 Żółkowska 2016, p. 218.

10 Jansen 2020, p. 37.

11 Van Wijnen 1996, p. 33.

12 Paterson \& Hughes 1999, p. 607; Imrie 2015, p. 478.

13 Carey 2015, p. 121.

14 Nussbaum 2006, p. 108-109.

15 Jansen 2020, p. 37. 
behoeften, zorgen en stemmen van mensen met een functiebeperking op gelijke voet met relatief gezonde mensen meenemen, vormen bij uitstek zulke rechten. Ook het sociale model kon echter op commentaar rekenen. Het heeft volgens critici te weinig oog voor de ongemakken die bij een lichamelijke of mentale functiebeperking zullen blijven horen, zelfs als de maatschappij geen barrières meer zou opwerpen. ${ }^{16}$ Heden ten dage zijn daarom vooral varianten van het sociale model, die verder kijken dan het louter opheffen van bestaande barrières, invloedrijk. Bekende voorbeelden zijn het mensenrechtenmodel, het hiernaast behandelde culturele model en de op mensen met een functiebeperking toegespitste interpretaties van de mogelijkhedenaanpak (capabilities approach) en kwetsbaarheidstheorie (vulnerability theory). ${ }^{17}$ Deze theorieën hebben belangrijke kenmerken gemeen wat betreft toegankelijkheid. Ze gaan er net als het sociale model van uit dat de maatschappij meer hindernissen opwerpt voor mensen met een functiebeperking in vergelijking met relatief gezonde mensen. Daarnaast beschouwen zij functiebeperkingen als deel van een spectrum waarop - gedurende een mensenleven - eenieder zich op termijn kan en zal vinden. ${ }^{18}$ Dientengevolge zijn de gesuggereerde stappen naar een toegankelijke wereld vaak op een universeel ontwerp (universal design) geënt. ${ }^{19}$ Dit streven naar universele toegankelijkheid van zowel de fysieke wereld als instituties zien we eveneens terug in het Verdrag inzake de rechten van personen met een handicap (verder: VN-verdrag Handicap), met name in artikel 3, 9 en $21 .{ }^{20}$ Het opnemen van dit streven in het verdrag vertaalt zich in de plicht voor verdragsstaten om een minimum aan toegankelijkheid van alle organisaties, zowel publiek als privaat, te eisen en te controleren. Men kan zelfs stellen dat toegankelijkheid als voorwaarde wordt gezien om alle andere fundamentele rechten te kunnen genieten. ${ }^{21}$

\section{Kwetsbaarheidstheorie}

Vanwege de beperkte ruimte die mij ter beschikking staat, zal ik in het vervolg van deze bijdrage kwetsbaarheidstheorie als rode draad nemen om de ervaringen en observaties met (on)toegankelijkheid uit de Forum-bijdrage hiernaast te duiden hoewel het resultaat met bijvoorbeeld de mogelijkhedenaanpak niet heel anders zou zijn. De centrale stelling van kwetsbaarheidstheorie is dat wij allen kwetsbare wezens zijn. ${ }^{22}$ We kunnen en zullen allen onderhevig zijn aan lichamelijke en men-

16 Crow 1996, p. 58; Jansen 2020, p. 37.

17 Degener 2017, p. 41-42; Nussbaum 2006; Hoppe, Kool \& Schippers 2011, p. 20; Fineman 2020, p. 55, n. 18.

18 Degener 2017, p. 43-44, 54-55; Nussbaum 2006, p. 160; Fineman 2008, p. 12. Voor een recent overzicht van de relatieve gezondheid van Nederlanders, zie: Marangos \& Kooiker 2019.

19 Cogdell 2015, p. 177.

20 Seatzu 2017, p. 226-228. Voor art. 3, met de algemene beginselen van het VN-verdrag Handicap, zie: Della Fina 2017, p. 120-121. Voor art. 9, over toegankelijkheid in het algemeen, zie: Seatzu 2017, p. 238-239. Voor art. 21, over de vrijheid van mening en meningsuiting en toegang tot informatie, zie: Cera 2017, p. 388-389.

21 Committee on the Rights of Persons with Disabilities, General Comment 2 (2014); Seatzu 2017, p. 230-231, 238-239.

22 Fineman 2008, p. 8. 
tale functiebeperkingen, maar ook geweld of discriminatie zijn nimmer uitgesloten. ${ }^{23}$ De frequentie en ernst waarmee dergelijke universele kwetsbaarheden zich manifesteren, hangt echter af van onze lichamelijke situatie en maatschappelijke positie. ${ }^{24}$ Deze twee factoren zijn volgens kwetsbaarheidstheoretici niet geheel los van elkaar te zien. Wij mogen dan allen kwetsbaar zijn, maar de huidige maatschappij is wél reeds ingericht op bepaalde kwetsbaarheden die normaal worden geacht, en niet op andere. ${ }^{25}$ Hoge stoepen houden bijvoorbeeld onvoorzichtige passanten onder auto's vandaan, maar vormen een dagelijks obstakel voor rolstoelgebruikers. ${ }^{26}$ De effecten van dergelijke obstakels cumuleren: een ontoegankelijke openbare ruimte beperkt navenant de afstand die rolstoelgebruikers kunnen forenzen. ${ }^{27}$ Zulk een ontoegankelijkheid geldt veelal ook instituties. Niet alleen worden de belangen van mensen die afwijken van de veronderstelde norm meestal onvoldoende meegenomen in de besluitvorming, maar er zijn vaak ook weinig mogelijkheden om deze lacune te remediëren. ${ }^{28}$ Om het eerdere voorbeeld te vervolgen: niet alleen de ontoegankelijkheid van de openbare ruimte is een probleem voor rolstoelgebruikers, maar ook in hoeverre hun belangen werden meegewogen in het beslissingsproces hieromtrent en de manieren waarop zij die ontoegankelijkheid effectief kunnen aankaarten. ${ }^{29}$ Zolang alleen bepaalde kwetsbaarheden vanzelfsprekend tot onze collectieve verantwoordelijkheid behoren en worden betrokken bij de afwegingen van de maatschappelijke instituties die zowel de publieke zaak bestieren alsmede de mogelijkheden voor betekenisvolle inspraak regelen, zullen manifestaties van onze universeel gedeelde kwetsbaarheid bepaalde groepen buitenproportioneel blijven raken. ${ }^{30}$ Mensen met een functiebeperking vormen zo'n groep, omdat zij - mede door de prevalente ontoegankelijkheid - met enige regelmaat afhankelijker zijn van de publieke infrastructuur, fysiek én institutioneel, dan relatief gezonde mensen.

De oplossing voor de vanzelfsprekendheid van publieke zorg voor sommige kwetsbaarheden en het verwaarlozen van andere, ligt volgens veel kwetsbaarheidstheoretici in een herijking van de collectieve verantwoordelijkheid van de samenleving, zoals deze wordt vormgegeven door onze maatschappelijke instituties. ${ }^{31}$ De weerbaarheid tegen kwetsbaarheden dient, in deze optiek, uitgebreid te worden naar groepen die deze nu missen. ${ }^{32}$ Of de maatschappij toegankelijk is, zou daarmee niet meer af moeten hangen van de maatschappelijke opvattingen du jour over het faciliteren van mensen met een functiebeperking. ${ }^{33}$ Toegankelijkheid voor iedereen behoort het uitgangspunt te zijn. ${ }^{34}$ Om het vorige voorbeeld af te sluiten: stoepen

Satz 2015, p. 517; Fineman 2020, p. 55, n. 18.

Fineman 2010, p. 269.

Satz 2015, p. 515.

Nussbaum 2006, p. 109, 113, 116-17, 188-89; Lippert-Rasmussen 2014, p. 39.

Dijkstra 2020a, p. 42.

Cooper 2015, p. 1341; Fineman 2014, p. 313; Fineman 2012, p. 1754.

Williamson 2015, p. 53; Hamelink \& Verme区 2021a, p. 48; Hamelink \& Verme区 2021b, p. 116-118.

Fineman 2008, p. 23.

Fineman 2010, p. 259-260.

Kirby 2006, p. 13, 55; Fineman 2008, p. 14.

Satz 2015, p. 520.

Kohn 2014, p. 6. 
kunnen zowel onvoorzichtige passanten als rolstoelgebruikers faciliteren. Kwetsbaarheidstheoretici beogen daarmee dus één opvatting, dat de kwetsbaarheden van mensen met een functiebeperking net zozeer tot onze collectieve verantwoordelijkheid behoren als die van relatief gezonde mensen - ook waar dit toegankelijkheid betreft - te verankeren. Men kan dit toegankelijkheidsstreven, dat breed gedeeld wordt tussen de theorieën die voortkomen uit het sociale model, kenschetsen als een mensenrechtenkwestie. ${ }^{35}$ Zo'n kenschetsing komt overeen met zowel de algemene ambitie van het VN-verdrag Handicap, volwaardige maatschappelijke deelname voor mensen met een functiebeperking, als de eerdergenoemde eisen die het stelt omtrent toegankelijkheid. ${ }^{36}$ Zoals we hiernaast konden lezen is het verwezenlijken van deze mensenrechtenambities geen sinecure.

\section{De fysieke wereld}

Bij discussies over toegankelijkheid is de fysieke wereld - en in het bijzonder de openbare ruimte - meestal het uitgangspunt. Kwetsbaarheidstheorie onthulde de voornaamste tekortkoming van deze benadering: de toegankelijkheid van de fysieke wereld hangt samen met de prioriteiten en het optreden van maatschappelijke instituties. Daarom kan alleen een geïntegreerde aanpak de kwetsbaarheden van mensen met een functiebeperking recht doen. Voordat we in de institutionele wereld aanbelanden, zal ik eerst de praktische ervaringen uit de Forum-bijdrage hiernaast aanvullen met twee inzichten vanuit kwetsbaarheidstheorie en één overweging met betrekking tot het VN-verdrag Handicap.

Het onderscheid tussen ouderen en mensen met een levenslange en levensbrede functiebeperking zal bij een aanpak vanuit kwetsbaarheidstheorie minder stevig worden aangezet dan hiernaast wordt gesuggereerd. Ouderen met kwalen zijn, in deze optiek, eenvoudigweg later in hun leven geconfronteerd met dergelijke kwetsbaarheden dan de laatstgenoemde groep en hun levensfase heeft invloed op hoe deze zich manifesteren. Met zoveel diversiteit zal het inrichten van, onder andere, de openbare ruimte met het oog op de kwetsbaarheden van álle mensen, nopen tot creativiteit en mogelijk het opgeven van bepaalde verworvenheden. Als rolstoelgebruikers en ouderen bijvoorbeeld hinder ondervinden van geleidelijnen kan men het trottoir verbreden. Dit zal dan soms ten koste gaan van terrassen en het autoverkeer. Gemotoriseerd vervoer is echter eveneens belangrijk voor mensen met een functiebeperking. Dus ook op het oog alomvattende oplossingen komen met hun eigen nadelen. Een aanpassing ten bate van mensen met een bepaalde functiebeperking zal sporadisch de vooruitgang in toegankelijkheid voor mensen met een andere functiebeperking, in ieder geval tijdelijk, kunnen frustreren. Universele toegankelijkheid zal dientengevolge niet op stel en sprong verwezenlijkt kunnen worden. Ondanks dit soort puzzels is vooruitgang onvermijdelijk. ${ }^{37}$ Het toezichthoudend comité bij het VN-verdrag Handicap wijst erop dat in ieder geval nieuwe gebouwen en infrastructuur in aanmerking komen voor een doordachtere aanpak, 
die de volwaardige maatschappelijke deelname van mensen met een functiebeperking faciliteert. ${ }^{38}$ Dezelfde nood voor een doordachte, geïntegreerde aanpak zien we in de institutionele wereld.

\section{De institutionele wereld}

Ook bij de institutionele wereld beperk ik mij tot drie aanvullingen op de Forum-bijdrage hiernaast. Deze aanvullingen betreffen de stilstand achter de ogenschijnlijke vooruitgang inzake de uitvoering van het VN-verdrag Handicap; de verplichtingen die mensen met een functiebeperking veelal krijgen opgelegd bij het mitigeren van hun kwetsbaarheden; en de risico's van selectief ingewonnen ervaringsdeskundigheid.

Elders heb ik aangetoond dat de ratificatie van het VN-verdrag Handicap en de daarmee gepaard gaande extra aandacht voor mensen met een functiebeperking, nog niet altijd heeft geleid tot wezenlijk andere aannames en handelwijzen bij instituties. De toegang tot zorg hangt bijvoorbeeld nog vaak samen met een beperkt aantal diagnoses, in plaats van een breder idee van functiebeperking. ${ }^{39}$ Daarnaast waarborgden de verkiezingen van maart 2021 de toegankelijkheid van het verkiezingsproces voor mensen met een functiebeperking minder dan voorgaande volksraadplegingen. ${ }^{40}$ Het belangrijkste voorbeeld betreft wellicht financiële bestaanszekerheid. Hier zien we dat veel mensen met een functiebeperking - zoals degenen die onder de Participatiewet vallen - verplichtingen krijgen opgelegd als zij inkomensvoorzieningen gebruiken die een volwaardige(re) maatschappelijke deelname mogelijk maken. ${ }^{41}$ Deze zogenoemde 'activerende' maatregelen dienen het verblijf in dit soort regelingen te beperken. ${ }^{42}$ Omdat de inrichting van de maatschappij veelal niet aansluit op de noden en talenten van mensen met een functiebeperking, worden velen mogelijkerwijs ten eeuwigen dage geactiveerd op deze manier. Deze situatie is wellicht mede ontstaan doordat de overwegingen van de wetgever zich regelmatig lijken te beperken tot de meest zelfredzame en daarmee meest zichtbare groep, waarbij de indruk wordt gewekt dat men zich onvoldoende bekommert om de gevolgen voor de mensen met de zwaarste functiebeperkingen. ${ }^{43}$ Sinds de invoering van de Participatiewet heeft namelijk ook het gros van deze laatste groep met dergelijke activerende maatregelen te maken; een klein contingent dat nog onder een milder regime valt, zoals de laatste WAJONG'ers, daargelaten. ${ }^{44}$

Vanuit het perspectief van kwetsbaarheidstheorie zou daadwerkelijke vooruitgang inzake de volwaardige maatschappelijke deelname van mensen met een functiebe-

Committee on the Rights of Persons with Disabilities, General Comment 2 (2014), par. 15 e.v.; Houtzager 2019, p. 13.

Dijkstra 2021a, p. 26, 29-30.

Dijkstra 2021b, p. 24-25.

Dijkstra 2020a, p. 43-44; Dijkstra 2021b, p. 25-27.

Van Echtelt 2020, p. 47.

Dijkstra 2020a, p. 44-45.

Dijkstra 2021b, p. 26; Kamerstukken II 2011/12, 33161, nr. 3, p. 3-4; Van Echtelt 2020, p. 45-46. Ter nuancering: ook de WAJONG kent haar eigen verplichtingen. Zie: Boetzelaer-Gulyas 2021, p. 229-230. 
perking moeten worden verwezenlijkt en dit zonder 'activerende' verplichtingen. De relatief gezonde mensen, op wier volwaardige deelname de maatschappij reeds is ingericht, hoeven in zijn algemeenheid immers ook geen tegenprestatie te leveren. Natuurlijk gelden de activerende maatregelen van regelingen zoals de Participatiewet ook voor de relatief gezonde mensen die van deze voorzieningen gebruikmaken. Maar zij kunnen meestal redelijkerwijs - hoewel niet altijd - verwachten dat zij niet hun hele leven van dit soort regelingen afhankelijk zullen blijven. Dit laatste is voor mensen met een (zwaardere) functiebeperking relatief vaker hun realiteit, juist omdat de maatschappij zich nog onvoldoende over hun kwetsbaarheden ontfermt. ${ }^{45}$ Daarnaast maken de activerende maatregelen binnen regelingen zoals de Participatiewet deel uit van een heel scala aan tegenprestaties waar mensen met een functiebeperking mee te maken hebben. De beschikbaarheid van hulpmiddelen, bijvoorbeeld via de Wet maatschappelijke ondersteuning, hangt tegenwoordig ook met enige regelmaat af van bepaalde tegenprestaties. ${ }^{46}$

Mijn derde en laatste aanvulling op de Forum-bijdrage hiernaast betreft ervaringsdeskundigheid. Deze dient breed te worden ingewonnen, waarbij er voldoende aandacht is voor de zwaardere functiebeperkingen.

\section{Ter conclusie}

Ondanks onmiskenbare vooruitgang is de wereld wat betreft toegankelijkheid voor mensen met een functiebeperking nog steeds gemankeerd. Burgers op een dergelijke wijze uitsluiten van het publieke leven, zowel de openbare ruimte als instituties, schuurt in liberale democratieën. ${ }^{47}$ Het is daarom geen toeval dat de mensenrechtelijke insteek - die mede naar voren kwam in de theorieën die ik in deze bijdrage heb opgevoerd - zo invloedrijk blijkt. ${ }^{48}$ Het moderne mensenrechtenkader is immers universeel en staat niet toe dat mensen groepsgewijs onttrokken worden aan het licht van het recht. ${ }^{49}$ Alleen als wij allen volwaardig aan de maatschappij kunnen deelnemen, kunnen wij allen onze mensenrechten volledig genieten. ${ }^{50}$ Toegankelijkheid is daarmee een recht en geen gunst. De oplossingen die binnen de behandelde theorieën worden aangedragen - hun voorgestelde pogingen voor universele toegankelijkheid - zijn dientengevolge ten minste het overwegen waard. Het uitgangspunt van universeel ontwerpen kan daarnaast deel zijn van een beweging die breder is dan het bestrijden van de huidige achterstelling van mensen met een functiebeperking. De kwestie van de toegankelijkheid van de zorg zal - tot op zekere hoogte - bijvoorbeeld ook spelen bij andere groepen die afwijken van de veronderstelde norm, zoals trans- en interseksepersonen. ${ }^{51}$

Dergelijke oplossingen komen, zoals ik reeds opmerkte, niet zonder hun eigen problemen. Mogelijke remedies hiervoor, die tevens besloten liggen in de besproken

45 Heekelaar \& Van Eldik 2021, p. 8.

46 Versantvoort \& Van Echtelt 2019, p. 246; Boetzelaer-Gulyas 2021, p. 147-150.

47 Imrie 2015, p. 481-482.

48 Carey 2015, p. 119.

49 Dijkstra 2020c, p. 1154.

50 Dijkstra 2021b, p. 21.

51 Dijkstra 2019, p. 1242. 
theorieën, omvatten onder andere maatwerk en een algemene ondergrens aan toegankelijkheid. Universeel ontwerpen hoeft namelijk geen uniformiteit te betekenen - creatieve en zelfs persoonlijke arrangementen liggen ook op tafel..$^{52}$ Daarnaast is de huidige onmogelijkheid van een daadwerkelijk universeel ontworpen publieke ruimte - het aanpakken van de kwetsbaarheid van de één verzaakt immers mogelijkerwijs die van de ander - niet noodzakelijkerwijs onze meest directe prioriteit. ${ }^{53}$ Men kan aanvankelijk focussen op het garanderen van een minimum aan toegankelijkheid voor eenieder - en dan vooral voor degenen die dit nu ontberen, zoals mensen met een functiebeperking. Hierbij zullen de ernstigste barrières het eerste sneuvelen. ${ }^{54}$ Daarbij past de aantekening dat men bij het slechten van dergelijke barrières en de eventuele creatieve en persoonlijke oplossingen die hiervoor (ten minste tijdelijk) nodig zullen zijn, niet het toegankelijkheidsprobleem terug moet leggen bij de persoon met een functiebeperking. Het betreft hier slechts haltes op weg naar algemeen gedeelde toegankelijkheid, geen terugkeer naar het normaliserings- of medische model. Desalniettemin zal het schipperen worden. Maar als men de inzichten van de hierboven gepresenteerde theorieën ter harte neemt, zal er geschipperd moeten worden met de belangen van álle mensen op het netvlies. Inclusief degenen met een functiebeperking en terwijl hun stemmen hoorbaar zijn in de besluitvorming. ${ }^{55}$

\section{Referenties}

Burch, S. \& K.E. Nielsen, 'History', in: R. Adams, B. Reiss \& D. Serlin (red.), Keywords for disability studies, New York: New York University Press 2015, p. 272-280.

Boetzelaer-Gulyas, I.A.M., Basisboek sociale zekerheid 2021, Deventer: Wolters Kluwer 2021.

Carey, A., 'Citizenship', in: R. Adams, B. Reiss \& D. Serlin (red.), Keywords for disability studies, New York: New York University Press 2015, p. 116-121.

Cera, R., 'Article 21 [Freedom of expression and opinion, and access to information]', in: Fina, V. della, R. Cera \& G. Palmisano (red.), The United Nations Convention on the Rights of Persons with Disabilities: a commentary, Cham: Springer 2017, p. 387-399.

Cogdell, C., 'Design', in: R. Adams, B. Reiss \& D. Serlin (red.), Keywords for disability studies, New York: New York University Press 2015, p. 174-177.

Cooper, F.R., 'Always already suspect: revising vulnerability theory', North Carolina Law Review 2015-93(5), p. 1339-1379.

Crow, L., 'Including all of our lives: renewing the social model of disability', in: C. Barnes \& G. Mercer (red.), Exploring the divide: illness and disability, Leeds: Disability Press 1996, p. 55-73.

Degener, T., 'A new human rights model of disability', in: Fina, V. della, R. Cera \& G. Palmisano (red.), The United Nations Convention on the Rights of Persons with Disabilities: a commentary, Cham: Springer 2017, p. 41-59.

Dijkstra, E., 'Het versmade strafrecht? Een breder perspectief op het toevoegen van geslachtskenmerken, genderidentiteit en genderexpressie aan de AWGB', Nederlands Juristenblad 2019-94(17), p. 1239-1245. 
Dijkstra, E., 'Wanneer je leven bepaald wordt door de wet: over handicap, regelgeving en identiteit', Handicap \& Recht 2020a-5(2), p. 41-46.

Dijkstra, E., 'De coronacrisis noopt tot meer expliciete aandacht van de Nederlandse staat voor het VN-Verdrag Handicap', NTM/NJCM-Bulletin 2020b-45(3), p. 377-380.

Dijkstra, E., 'Laat ouderen over de toekomst stemmen', Nederlands Juristenblad 2020c, 95(16), p. 1151-1155.

Dijkstra, E., 'Addressing problems instead of diagnoses: reimagining liberalism regarding disability and public health,' Netherlands Journal of Legal Philosophy 2021a-50(1), p. 2239.

Dijkstra, E., 'Het standstillbeginsel en de uitvoering van het VN-Verdrag Handicap', Handicap \& Recht 2021b-6(1), p. 21-27.

Echtelt, P. van, 'Iedereen aan het werk? De beleidstheorie achter de Participatiewet', in: H. Bosselaar (red.), Met andere ogen: onderzoekers over 5 jaar Participatiewet, Den Haag: Boom Bestuurskunde 2020, p. 45-61.

Emens, E., 'Accommodation', in: R. Adams, B. Reiss \& D. Serlin (red.), Keywords for disability Studies, New York: New York University Press 2015, p. 65-71.

Fina, V. della, 'Article 3 [general principles]', in: V. della Fina, R. Cera \& G. Palmisano (red.), The United Nations Convention on the Rights of Persons with Disabilities: a commentary, Cham: Springer 2017, p. 119-136.

Fineman, M.A., 'The vulnerable subject and the responsive state', Emory Law Review 201060(2), p. 251-275.

Fineman, M.A., 'Beyond identities: the limits of an antidiscrimination approach to equality', Boston University Law Review 2012-92(6), p. 1713-1770.

Fineman, M.A., 'Vulnerability, resilience, and LGBT youth', Temple Political \& Civil Rights Law Review 2014-23(2), p. 307-330.

Fineman, M.A., 'Beyond equality and discrimination', SMU Law Review Forum 2020-73(1), p. 51-62.

Hamelink, W. \& L. Vermij, 'De sociale kant van toegankelijkheid', in: L. Vermeij \& W. Hamelink (red.), Lang niet toegankelijk: ervaringen van Nederlanders met een lichamelijke beperking als spiegel van de samenleving, Den Haag: Sociaal en Cultureel Planbureau 2021a, p. 44-53.

Hamelink, W. \& L. Verme区, 'Sport en civil society', in: L. Vermeij \& W. Hamelink (red.), Lang niet toegankelijk: ervaringen van Nederlanders met een lichamelijke beperking als spiegel van de samenleving, Den Haag: Sociaal en Cultureel Planbureau 2021b, p. 101-118.

Heekelaar, M. \& I. van Eldik, Ondersteuning en dienstverlening aan langdurig bijstandsgerechtigden: Verkenning, Utrecht: Berenschot 2021.

Hoppe, S., J. Kool \& A. Schippers, Disability studies in Nederland: verbinding in de context, Utrecht: Disability Studies in Nederland 2011.

Houtzager, D.C., 'Uitleg van het VN-Verdrag Handicap: toepassing van de General Comments van het VN-Comité Handicap in Nederland,' Handicap \& Recht 2019-4(1), p. 9-14.

Imrie, R., 'Space', in: R. Adams, B. Reiss \& D. Serlin (red.), Keywords for disability studies, New York: New York University Press 2015, p. 478-482.

Jansen, J., 'De "verantwoordelijke beperkte": de beeldvorming van jonggehandicapten in de Participatiewet', in: H. Bosselaar (red.), Met andere ogen: onderzoekers over vijfjaar

Participatiewet, Den Haag: Boom Bestuurskunde 2020, p. 29-44.

Kirby, P., Vulnerability and violence: the impact of globalization, London: Pluto Press 2006.

Kohn, N.A., 'Vulnerability theory and the role of government', Yale journal of Law and Feminism 2014-26(1), p. 1-27.

Lippert-Rasmussen, K., Born free and equal? A philosophical inquiry into the nature of discrimination, Oxford: Oxford University Press 2014.

Longmore, P.K., Why I burned my book and other essays on disability, Philadelphia: Temple University Press 2003. 
Marangos, A. \& S. Kooiker, 'Gezondheid en zorg', in: A. Wennekers e.a. (red.), De sociale staat van Nederland: 2019, Den Haag: Sociaal en Cultureel Planbureau 2019, p. 164-187.

Nepveux, D., 'Activism', in: R. Adams, B. Reiss \& D. Serlin (red.), Keywords for disability studies, New York 2015, p. 73-83.

Nussbaum, M.C., Frontiers of justice: disability, nationality, species membership, Cambridge: Harvard University Press 2006.

Paterson, K. \& B. Hughes, 'Disability studies and phenomenology: the carnal politics of everyday life', Disability and Society 1999-14(5), p. 597-610.

Satz, A.B., 'Vulnerability', in: R. Adams, B. Reiss \& D. Serlin (red.), Keywords for disability studies, New York: New York University Press 2015, p. 517-521.

Seatzu, F., 'Article 9 [accessibility]', in: V. della Fina, R. Cera \& G. Palmisano (red.), The United Nations Convention on the Rights of Persons with Disabilities: a commentary, Cham: Springer 2017, p. 225-242.

Silvers, A., 'A fatal attraction to normalizing: treating disabilities as deviations from "species- typical" functioning', in: E. Parens (red.), Enhancing human traits, Washington: Georgetown University Press 1998, p. 95-123.

Versantvoort, M. \& P. van Echtelt, 'Synthese en aandachtspunten', in: P. van Echtelt, K. Sadiraj, S. Hoff, S. Muns, K. Karpinska, D. Das \& M. Versantvoort (red.), Eindevaluatie van de Participatiewet, Den Haag: Sociaal en Cultureel Planbureau 2019, p. 238-256.

Wijnen, A. van, 'Men wordt niet gehandicapt geboren', in: A. van Wijnen, Y. Koster-Dreese \& A. Oderwald (red.), Trots en treurnis: gehandicapt in Nederland, Amsterdam: Babylon/ De Geus 1996, p. 27-39.

Williamson, B., 'Access', in: R. Adams, B. Reiss \& D. Serlin (red.), Keywords for disability studies, New York: New York University Press 2015, p. 53-59.

Żółkowska, T., 'Construction of intellectual disability: (de)construction of the social role of intellectually disabled persons', International Journal of Developmental Disabilities 201662(4), p. 213-223. 